\title{
Geometric analysis of partial differential equations and several complex variables: in honor of Nick Hanges
}

\author{
John D'Angelo ${ }^{1}$ Paulo D. Cordaro ${ }^{2} \cdot$ Xiaojun Huang ${ }^{3} \cdot$ Nordine Mir $^{4}$
}

Published online: 10 June 2020

(c) Springer Nature Switzerland AG 2020

Every two years, since 2001, the University of São Paulo and the Federal University of São Carlos organize a workshop in the small town of Serra Negra, Brazil, focusing on geometric analysis of partial differential equations and several complex variables. Nick Hanges attended five of these meetings, one remotely when he was ill, and invariably presented strong results and asked penetrating questions. Sadly Nick passed away in July, 2019. At the Meeting held in August 2019, the four editors decided to create a special issue of Complex Analysis and its Synergies in his honor. We are delighted by the fourteen papers appearing in this topical issue

Nick's broad research interests included such topics as the propagation of analytic singularities, CR and hypo-analytic structures, locally integrable structures, Bergman and Szëgo kernels, classes of nonlinear equations and the analyticity of their solutions, and the study of the analytic hypoellipticity for sums of squares operators. In all of these topics he, either alone or in collaboration with J. Sjöstrand, F. Treves,
H. Jacobowitz, G. Francsics, and A. Himonas, obtained significant results. We mention two examples of fundamental results Nick obtained in microlocal analysis. His Annals paper with Sjöstrand on microlocal propagation of analytic singularities remains influential. His work with Treves on propagation of $\mathrm{CR}$ extendability has been extensively used in the theory of CR functions as well as mappings and has been often cited in the Serra Negra meetings.

Nick was a strong analyst with excellent taste in mathematics. We know he would be pleased with this volume. We thank him for his contributions to mathematics and his inspiration to all of us.

Publisher's Note Springer Nature remains neutral with regard to jurisdictional claims in published maps and institutional affiliations.
Paulo D. Cordaro

cordaro@ime.usp.br

1 Department of Mathematics, University of Illinois, $1409 \mathrm{~W}$. Green St., Urbana, IL 61801, USA

2 IME-USP, São Paulo, SP, Brazil

3 Department of Mathematics, Rutgers University, New Brunswick 08903, NJ, USA

4 Department of Mathematics, Texas A\&M University at Qatar, Education City, Doha, Qatar 